\title{
Do Open-Minded Student Teachers Have More Favorable Attitudes Towards Different Dimensions of Heterogeneity?
}

\author{
The Relationship Between the Big Five Personality Traits and Attitudes Towards Ethnic-Cultural, Social and \\ Performance-Related Heterogeneity \\ Marcus Syring ${ }^{1}$, Teresa Tillmann ${ }^{1}$, Sabine Weiss ${ }^{1}$ \& Ewald Kiel ${ }^{1}$ \\ ${ }^{1}$ Chair for School and Teacher Research, Ludwig-Maximilians-University of Munich, Germany \\ Correspondence: Marcus Syring, Chair for School and Teacher Research, Ludwig-Maximilians-University of \\ Munich, Leopoldstraße 13, 80802 Munich, Germany. Tel: 49-89-2180-4844. E-mail: marcus.syring@edu.lmu.de
}

Received: February 19, 2018 Accepted: March 13, 2018 Online Published: March 20, 2018

doi:10.5539/jedp.v8n1p133 URL: http://doi.org/10.5539/jedp.v8n1p133

\begin{abstract}
The present study aims at investigating student teachers' attitudes towards heterogeneity, which represent one part of teachers' profession and determine future teacher action. Particularly, it addresses research gaps regarding the relationship between attitudes and personality traits such as the Big Five, which are also important in the field of teacher professionalism. Through confirmatory factor analysis, the validity of an existing measurement instrument of attitudes was verified in a sample with 294 student teachers. Personality traits represented significant predictors of some of the attitudes measured, but were only able to explain relatively little variance. Practical implications for teacher training are discussed.
\end{abstract}

Keywords: attitudes, Big Five personality traits, heterogeneity, measurement, teacher professionalism, structural equation modelling

\section{Introduction}

Increasing heterogeneity in classrooms is not just a current European, but rather a global phenomenon. Among other reasons, strong migration movements, individualisation trends in society, globalisation, but also demands related to education policies (e.g., United Nations, 2006) and resulting changes in the education systems lead to its intensification (Paine, Bloemeke, \& Aydarova, 2016). These developments are manifested in different forms of heterogeneity: ethno-cultural, social and performance-related heterogeneity as it will be explained below. Consequently, schools and teachers have to react to these existing different forms of heterogeneity. This is particularly important since the increased heterogeneity also leads to an increase in uncertainty in the pedagogical action of teachers.

When dealing with heterogeneity in the classroom, attitudes are particularly important for a successful teaching. This is true in addition to the role of various resources and future teachers' training (Carter \& Darling-Hammond, 2016). Furthermore, teachers' success is also found to be associated with successful teaching and learning processes for students (De Boer, Pijl, \& Minnaert, 2011). This is why in the last few years teacher and school research has increasingly focused on attitudes. However, studies show an apparent contradiction: Despite fundamentally positive attitudes towards heterogeneity (see the review by Avramidis \& Norwich, 2002), hesitating to even rejecting attitudes regarding concrete implementation of inclusive schooling are found among teachers (e.g., Ring, 2005). It could be assumed that this discrepancy may be attributable to the fact that existing instruments measuring attitudes only represent a fraction of this construct, namely the cognitive component, but not other aspects of attitudes, such as the behavioural facet (Eagly \& Chaiken, 1993). This is highly criticized due to the fact that focusing only on the cognitive dimension results in a shortened picture of the attitudes. The present study investigates the emerging desiderata of mapping attitudes towards heterogeneity with regard to all dimensions.

Similarly, an investigation of influences of teachers' and student teachers' personal factors on those attitudes also displays a research gap. Among the small number of studies analysing this relationship, results are relatively limited to migrant background, gender, and self-efficacy (see the review by Dignath, 2017). Personality traits, such as those included in the Five-Factor Model of Personality (FFM; McCrae \& Costa, 1990), which have been found 
to play an important role in other areas of research, have not been considered with regard to attitudes yet. Those personality characteristics can be described as involving '....differences among individuals in a typical tendency to behave, think, or feel in some conceptually related ways, across a variety of relevant situations and across some fairly long period of time' (Ashton, 2013, p. 27). In the field of teacher behaviour, the Big 5 have not yet been considered in this context. The present paper aims at closing these research gaps.

In the following, the theoretical background as well as the current research on attitudes, heterogeneity and the traits in the FFM will be presented. Subsequently, the resulting research questions of this study, methods and results are presented and finally discussed with a focus on teacher education and training as well as recruitment. Restrictions of the study are described and discussed in the end of the paper.

\section{Theoretical Background}

The way teachers deal with heterogeneity is dependent on their professionalism. On the one hand this professionalism can theoretically be described with professional knowledge and competences. This can be seen within established models in the field of professional research which include teachers' attitudes. On the other hand, however, another suitable approach represents personality research: Which personality characteristics in teachers are beneficial for handling the uncertainty resulting from heterogeneity and diversity? The presented study aims at taking into account both directions by answering the question which personality traits have positive effects on handling heterogeneity.

\section{Attitudes and Teaching Practice}

\subsection{Attitudes}

Attitudes are considered as a predisposition to react positively or negatively towards some person, object, idea, etc. They represent action-regulating factors, which influence an individual's choice (Eagly \& Chaiken, 1998; Wood, 2000). Consequently, they are important predictors of behaviour (e.g., Ajzen \& Fishbein, 2000; Pajares, 1992). Attitudes are often defined in terms of multi component models (Zanna \& Rempel, 1988). Research on attitudes suggests a differentiation of different facets, including a cognitive, a motivational-affective and a behavioural component (Eagly \& Chaiken, 1993; Maio \& Haddock, 2010; Smith \& Mackie, 2010; Rosenberg \& Hovland, 1960). Furthermore, it is assumed that attitudes always relate to a specific object (Ajzen, 2001). Consequently, one cannot speak of 'attitudes to heterogeneity' in general, but rather have to take into account the concrete form of heterogeneity (i.e., ethno-cultural, social, performance etc.) in a particular situation. The present study takes into account both aspects and investigates different factors, including dimensions of attitudes (i.e., cognitive, motivational-affective and behavioural) as well as facets of heterogeneity (i.e., ethno-cultural, social, and performance-related), as set out below.

Attitudes and teaching practice. The importance of attitudes in the field of teaching is reflected in the fact that those are one of the core elements in teacher education in models of professional competence (e.g., Goodman, Arbona, \& Dominguez de Rameriz, 2008). In line with the definition of attitudes described above, attitudes in the teaching profession can be defined as 'implicit or explicit conceptions about school- and learning-related matters that influence their perceptions of the environment and their behaviors' (Kunter, Klusmann, Baumert, Richter, Voss, \& Hachfeld, 2013). Summarizing the existing findings of international research on teachers' attitudes, those are found to be important for the design of and interaction in teaching-learning processes (Richardson, 1996). In particular, mediated through lesson planning and instructional design, teachers' attitudes play an important role for students' success in learning (e.g., Voss, Kleickmann, Kunter, \& Hachfeld, 2013).

Attitudes towards heterogeneity. In public as well as in scientific discussions, three categories of heterogeneity are currently considered: ethno-cultural, social and performance-related heterogeneity. These three categories are briefly explained and discussed with regard to existing research on attitudes below.

Ethno-cultural heterogeneity. Ethno-cultural heterogeneity in the classroom can be defined as students' diversity with regard to their cultural background (Mercado, 2001). This includes aspects like migration history, first/second language, cultural, or religious affiliation, and is always associated with differing interests, values, or convictions, to only name a few examples, which can be relevant to school performance (e.g., PIRLS, PISA, TIMSS, etc.). Recent studies indicate that handling interculturalism and dealing with migration in schools is associated with significant challenges for teachers (Kiel, Syring \& Weiss, 2017). Within the research field on attitudes, only a few studies explicitly deal with ethno-cultural heterogeneity and attitudes (Hachfeld et al., 2013; Taylor \& Sobel, 2001).

Social heterogeneity. According to the theory of capital by Bourdieu (1979), background differences between individuals arise due to a different degree of social capital. Furthermore, Bourdieu suggested a link between social 
and economic capital that is often defined as socioeconomic status (SES), which, in turn, is assumed to influence students' performance in school as well. Evidence for this relationship between the status of parents (i.e., SES) and students' school performance was found in numerous large scale studies, such as PIRLS, PISA, and TIMSS (for an overview, see Blossfeld, Bos, Lenzen, Müller-Böling, Oelkers, Prenzel, \& Wößmann 2007). However, studies analysing the role of social heterogeneity in schools, teaching, and learning are still rare and display a research gap.

Performance-related heterogeneity. A third form of heterogeneity represents the variety of students' performance. In particular, it describes differences in performance independent of age and education levels (Blossfeld, et al., 2007). This form displays a particular challenge for teachers, who have to respond adequately to the increased heterogeneity of performance through internal measures of differentiation.

Measuring attitudes. In the field of research on attitudes, many instruments can be found. In most cases, however, these include attitudes towards inclusion (see Avramidis \& Norwich, 2002) and at the same time only analyse the cognitive component of attitudes. Commonly used instruments capture attitudes towards inclusion or the inclusive training of children and young people with disabilities per se. Among others, the following scales can be found in the international field:

- $\quad$ TATI (Teacher Attitude to Inclusion Scale; Bryer, Grimbeek, Beamish, \& Stanley, 2004)

- $\quad$ MTAI (My Thinking about Inclusion Scale; Stoiber, Gettinger, \& Goetz, 1998)

- $\quad$ SACIE (Sentiments, Attitudes and Concerns about Inclusive Education; Loreman, Sharma, Earle, \& Forlin, 2007)

Furthermore, these attitudes are often combined with inclusion-related self-efficacy measurements, such as the TEIP questionnaire (Teacher Efficacy for Inclusive Practices; Sharma, Loreman, \& Forlin, 2011).

A first study, which explicitly examines student teachers' heterogeneity-related attitudes on the basis of different forms of heterogeneity and takes into account the multi-dimensionality of attitudes, was conducted at Technical University Dortmund in Germany (Gebauer, McElvany, \& Klukas, 2013). Based on theoretical conceptualisations by Eagly and Chaiken (1993; see section on attitudes above), the scale includes three underlying levels of attitudes (i.e., cognitive, motivational-affective and behavioural level) as well as the three different kinds of heterogeneity (i.e., social, ethno-cultural, performance-related) simultaneously. In addition, Gebauer and colleagues (2013) further divided the cognitive and the motivational-affective facets into two more specific sub-facets, resulting in a total of five facets of attitudes. Taking these five factors and the three aforementioned forms of heterogeneity together, the scale by Gebauer and colleagues results in a total of 15 subscales in which each subscale is measured by five items. Table 1 displays an overview of all levels and aforementioned subscales.

Table 1. Structural framework of the instrument measuring attitudes towards heterogeneity in students

\begin{tabular}{|c|c|c|c|c|c|c|}
\hline & & \multicolumn{5}{|c|}{ Factor of attitude } \\
\hline & & \multicolumn{2}{|c|}{ Cognitive } & \multicolumn{2}{|c|}{ Motivational-affective } & \multirow{2}{*}{$\begin{array}{l}\text { Behavioural } \\
\text { Competence } \\
\text { to act }\end{array}$} \\
\hline & & Benefit & Cost & $\begin{array}{l}\text { Negative } \\
\text { emotions }\end{array}$ & $\begin{array}{l}\text { Intrinsic } \\
\text { motiva-tion }\end{array}$ & \\
\hline \multirow{3}{*}{$\begin{array}{l}\text { Form of } \\
\text { heterogeneity }\end{array}$} & social & 5 items & 5 items & 5 items & 5 items & 5 items \\
\hline & ethnic-cultural & 5 items & 5 items & 5 items & 5 items & 5 items \\
\hline & Perfor-mance-related & 5 items & 5 items & 5 items & 5 items & 5 items \\
\hline
\end{tabular}

Research findings suggest that the scale's psychometric properties, in particular its reliability and validity, can be interpreted as acceptable to good (see also research question 1 in this paper). This was further supported by a successfully conducted confirmatory validation of the factorial structure based on multi-level factor analyses (Merk, Bohl, Cramer, Dai, \& Syring, in press).

Attitudes and personal factors. One of the most recent literature reviews in which existing literature on attitudes towards heterogeneity was investigated, is the one conducted by Dignath (2017). Organizing the existing findings revealed evidence for three broad findings and research areas in the field: First, positive correlations between attitudes and self-efficacy as well as teacher motivation have been found. As a second aspect, she found that in only one study the effect of teachers' own migrant background on their attitudes toward heterogeneity was analysed. Furthermore, there are three studies in which more positive attitudes towards heterogeneity in female 
teachers compared to their male colleagues were found (see also Yildirim, 2012). With regard to other personality-related factors, such as the widely accepted Big Five personality traits, studies investigating the relationship with attitudes towards heterogeneity are still rare. The present research study aims at addressing this research gap.

\subsection{Big Five Personality Traits}

Development and measurement of the Five-Factor Model (FFM) of personality. The FFM and related personality traits, also called the 'Big Five' (on a global level firstly suggested by Goldberg, 1981) have been widely accepted in the scientific field and applied in numerous studies across various fields (see for example an overview of literature by Gurven, Rueden, Massenkoff, Kaplan, \& Vie, 2013; or the meta-analyses by Judge, Heller, \& Mount, 2002). The formation of particular traits with which people can be described and grouped in order to realize such comparisons, represents one of the various paradigms within the complex field of personality (e.g., Asendorpf, 2007; see also Introduction). Among other approaches that have been applied in the field, the development of the Five-Factor Model of personality followed the lexical approach, which is based on the assumption that individual differences can be represented through language and descriptive adjectives (e.g., Ashton, 2013; John, Naumann, \& Soto, 2008). Three of the most popular findings revealed on the basis of this approach are the solutions by Cattell (e.g., 1947), Goldberg (1992) and the five-factor solution (Tupes \& Christal, 1992), which later became the Big Five personality traits. Despite the fact that different names of the traits have been and are still frequently discussed in the scientific literature (e.g., Funder, 2001), the descriptions of the Big Five by McCrae and Costa (1990), using the words extraversion, neuroticism, openness to experiences, agreeableness, and conscientiousness as descriptors, have been accepted and widely used in scientific personality research. In order to measure these factors, various questionnaires have been developed, which range from a 240-item version, such as the NEO-Personality Inventory Revised (NEO PI-R; Costa \& McCrae, 1992) to the Big Five Inventory with 44 items (BFI; John, Donahue, \& Kentle, 1991) or a short 10-item version (Rammstedt \& John, 2007). The resulting trait structure has been supported in various languages (for an overview, see Ostendorf \& Angleitner, 1994) and across different cultures (for an overview of research, see Gurven et al., 2013). Table 2 depicts a summary of the personality traits in the FFM as suggested by McCrae and Costa (1990) with adjectives used to describe the particular trait.

Table 2. Big Five Personality traits and related descriptors for every factor (from: McCrae \& John, 1992, pp. 178-179.)

\begin{tabular}{ll}
\hline Big Five personality factor & Descriptors \\
\hline Extraversion (E) & talkative, active, energetic, outgoing \\
Neuroticism (N) & anxious, self-pitying, unsTable, touchy \\
Openness to Experiences (O) & artistic, curious, insightful, original \\
Agreeableness (A) & generous, trusting, appreciative, sympathetic \\
Conscientiousness (C) & efficient, organized, responsible, planful \\
\hline
\end{tabular}

The Big Five Personality Traits and Teacher Behaviour. Because the five traits described above are assumed to represent a variety of different behavioural patterns (e.g., John et al., 2008), they also have an impact on behaviour in general and consequently also on that of teachers. This has already been suggested within the aforementioned competence model by Baumert and Kunter (Kunter et al., 2013) in which personality factors are one aspect related to competences. Empirical research conducted in this regard revealed evidence for the fact that all five personality traits significantly influence teachers' attitudes towards knowledge sharing. In comparison, all traits but conscientiousness also significantly influence knowledge sharing behaviour (Agyemang, Dzandu, \& Boateng, 2016). A similar relationship was found with conscientiousness (Cho, $\mathrm{Li}, \& \mathrm{Su}, 2007$ ) as well as openness to experience and agreeableness (Matzler, Renzl, Mueller, Herting, \& Mooradian, 2008) in non-teacher, organizational samples.

Similarly, teacher caring in a sample of college faculty teachers has been found to be negatively related to neuroticism. On the contrary, positive correlations were found with extraversion, agreeableness and conscientiousness (Teven, 2007). Furthermore, in a study comparing Chinese and American teachers on the basis of narratives, Gao and Liu (2013) revealed evidence for the fact that effective teachers are 'agreeable, caring, friendly, honest, and respectful' (p. 92) and perceive 'adaptability, enthusiasm, fairness, [...], patience and 
responsibility' (p. 92) as important in order to be effective. This was not only true for both cultures, but also lead to the conclusion 'that teachers who possess and demonstrate some, if not all, of these qualities, regardless of country and gender, are more likely to establish connectedness with students, engage students in teaching and learning process, and thus bring about desired school outcomes' (p. 92).

With regard to findings on the relationship between the Big Five personality traits and certain attitudes in general as well as attitudes towards different forms of heterogeneity, studies are still rare. Although studies within the political area, also including attitudes, exist (for an overview of studies, see Gerber, Huber, Doherty, \& Dowling, 2011), investigations on relations of personality traits and attitudes towards heterogeneity have not been conducted so far.

\section{Research Questions}

As the sections above show, two main research gaps can be found in the literature:

- Research investigating teachers' and student teachers' general attitudes towards heterogeneity, taking into account the different dimensions of heterogeneity, and

- research investigating the effects of the Big Five personality traits on attitudes towards heterogeneity.

The present research paper addresses both research gaps and aims at answering the resulting three research questions:

(1) Can the model of the three dimensions of attitudes (i.e., ethno-cultural, social, and performance-related) and the five facets of heterogeneity (i.e., benefit, costs, negative emotions, intrinsic motivation, competence) be confirmed (validity of the instrument)?

(2) How are student teachers' attitudes towards heterogeneity and the Big Five personality traits distributed in the present study (separately for each subscale)?

(3) What effects do the Big Five personality traits have on the five facets of attitudes towards heterogeneity?

a. What effect do all Big Five personality traits (taken into consideration simultaneously) have on the five types of attitudes towards heterogeneity separately?

b. What effects do the individual Big Five personality traits have on the five types of attitudes towards heterogeneity (taken into consideration simultaneously)?

\section{Method}

\subsection{Data Collection and Sample}

A total of 309 student teachers were asked to participate voluntarily and anonymously in the present study during a compulsory introductory lecture offered specifically for student teachers at a big university in Bavaria, Germany, in December 2015. Participation was achieved by filling in a paper-pencil version of a questionnaire. Prior to students' participation, it has been made clear by the responsible researchers that a decision to not participate does not result in any disadvantages.

During a first data cleaning process, participants, who did not answer up to $5 \%$ of the items (indicated as missing values) were taken out of the data set, which resulted in a first elimination of 15 student teachers, representing less than $5 \%$ of the sample. Consequently, the final sample size consists of $N=294$ student teachers of a total of five school types common within the German education system (elementary schools, special needs education as well as the three high school types general secondary, intermediate secondary and grammar schools). While one person answered the question about their gender with 'other', the majority of participants (i.e., 74\%) are female. Participants' average age was $21.81(S D=3.75)$ with students attending the third semester $(M=3.18, S D=1.85$, range of semesters: 1 - 10) on average. Due to the fact that $79 \%$ of all participants were between their first and their third semesters, students represented in the study are defined as novices or beginner teachers. With regard to their cultural background, $20 \%$ of all participants were identified as falling into a category of having an own migrant background. Specifically, $11 \%$ reported that one parent was born outside of Germany and $9 \%$ indicated to be born in a family with both parents not being born in Germany.

\subsection{Scales and Measurements}

Student teachers' attitudes towards heterogeneity were measured using the scale developed by Gebauer and colleagues (2013; see chapter 2.1 for more detailed information). All 25 items for each form of heterogeneity are answered on a 4-point Likert scale that ranges between 0 (= 'does not apply at all') to 3 (= 'totally applies'). Reliability measures (i.e., Cronbach's Alpha) as well as one example item for each of the levels of attitudes 
towards heterogeneity can be found in Table 3. It is important to note at this point that for the three different forms of heterogeneity (i.e., social, ethical-cultural and performance-related) only the first half of the sentence (in italics within the column displaying example items) changes throughout the scale, while the second part stays the same across those levels.

Table 3. Scales, numbers of items, example items and form of heterogeneity as well as range of reliability measures (Cronbach's alpha) of scale on attitudes towards heterogeneity developed by Gebauer et al. (2013)

\begin{tabular}{llll}
\hline Subscale & Items & $\begin{array}{l}\text { Example item } \\
\text { and form of heterogeneity }\end{array}$ & $\begin{array}{l}\text { Range of Cronbach's Alpha } \\
\text { across } \\
\text { heterogeneity) }\end{array}$ \\
\hline Benefit & 5 & $\begin{array}{l}\text { Students benefit by lessons in culturally heterogeneous groups } \\
\text { with regard to the development of their interests. } \\
\text { (form of heterogeneity: ethnic-cultural) }\end{array}$ & $.71-.76$ \\
\hline Costs & 5 & $\begin{array}{l}\text { Social heterogeneity within school classes is one of the biggest } \\
\text { problems in our education system. } \\
\text { (form of heterogeneity: social) }\end{array}$ & $.72-.77$ \\
\hline $\begin{array}{l}\text { Negative } \\
\text { emotions }\end{array}$ & 5 & $\begin{array}{l}\text { With regard to performance-related heterogeneity within school } \\
\text { classes impedes the goal of an ideal facilitation of learners. } \\
\text { (form of heterogeneity: performance-related) }\end{array}$ & $.82-.86$ \\
\hline $\begin{array}{l}\text { Intrinsic } \\
\text { motivation }\end{array}$ & 5 & $\begin{array}{l}\text { The cultural heterogeneity within our school classes will be } \\
\text { stimulating for me during day-to-day teaching. } \\
\text { (form of heterogeneity: ethnic-cultural) }\end{array}$ \\
\hline Competence & 5 & $\begin{array}{l}\text { With regard to teaching socially heterogeneous classes I am } \\
\text { confident that I will be able to respond well to students' } \\
\text { individual problems.(form of heterogeneity: social) }\end{array}$ \\
\hline
\end{tabular}

On the other hand, as the second instrument applied, personality characteristics were measured using an established German translation of the Big Five Inventory with ten items (BFI-10; original scale from Rammstedt, \& John, 2007; German translation by Rammstedt, Kemper, Klein, Beierlein, \& Kovaleva, 2014), which is answered on a 5-point Likert-scale, ranging from 0 (= 'does not apply at all') to 4 (= 'totally applies'). The scale was developed based on the 44-item version of the Big Five Inventory (BFI; John, Donahue, \& Kentle, 1991). As part of the development process, the two items with the best psychometric properties have been taken out for every personality trait and summarized in this short version. Evidence for acceptable scores supporting the scale's reliability and validity have already been empirically revealed in an US-American and a German sample (e.g., Rammstedt \& John, 2007). However, problems related to these properties, mainly caused by the scale's short length, have already been communicated. Based on this issue, reliability scores were therefore measured using item-total correlations and test-retest reliability measures, which resulted in findings, which, for example, revealed that the short version captures $70 \%$ of the variance of the original version of the BFI. Based on these findings, the instrument has been interpreted as appropriate (e.g. Rammstedt \& John, 2007; Ryser, 2015). Due to the design of the present study, the replication of such analyses was not possible, leading to the lack of reported reliability scores in this research paper.

\subsection{Statistical Analyses}

All statistical analyses have been conducted using IBM's statistic software SPSS for Windows. Furthermore, the structural equation models were built using the program SPSS Amos for Windows. In order to analyse the scale's validity as an answer to the first research question, a confirmatory factor analysis in the form of a structural equation model was conducted. As a result for the second research question, descriptive statistics are reported. Furthermore multiple regression analyses and structural equation modelling were applied in order to reveal findings in support of research questions $3 a$ and $3 b$.

Despite a first elimination of participants with missing values over $5 \%$ (see chapter 4.1 for more detailed information), there is still a small number of missing values to be found within the remaining final data set. 
Specifically, 61 missing values could not be prevented, which represents a percentage of 0.24 based on all participants and items relevant for the present study. In order to investigate whether these missing values are a random sub-sample or follow some kind of specific underlying pattern, Little's (1988) MCAR-test ('Missing Completely At Random') was applied. Because the result revealed an insignificant score $\left(p=.674 ; \chi^{2}=2801.438\right.$; $d f=2836$ ) it can be assumed that leaving these scores in the sample would not significantly bias the results (see also Dong \& Peng, 2013, p. 3), which lead to the decision of leaving those scores in the data set used for statistical analyses.

\section{Results}

The first research question aimed at analysing the validity of the scale measuring attitudes towards heterogeneity as developed by Gebauer and colleagues (2013). On the basis of a confirmatory factor analysis, a structural equation model for all forms of heterogeneity including the five factors of attitudes was developed using the statistics program IBM SPSS Amos. Based on a maximum likelihood approach, which is common in structural equation modelling (e.g., Byrne, 2009), resulting fit indices are calculated and interpreted with regard to how well the data fit the suggested model. Among the various fit indices that have been suggested in the literature and are partly based on various conditions (e.g., Lei \& Wu, 2007) the following indices are applied in the present study: Chi-square test describing the overall goodness of fit of the model, the comparative fit index (CFI) and RMSEA. In order to interpret the resulting values, cut-off values as suggested by Hu and Bentler (1999) are applied. These indices are listed for all three models representing the three forms of heterogeneity (i.e., social, cultural and performance-related) in Table 4 below. Looking through the estimates and fit indices in Table 4, it can be seen that all models reaches fit index values that are good to acceptable.

Table 4. Three models (based on the three type of heterogeneity) and the respective fit indices revealed in the confirmatory factor analysis using structural equation modelling based on Gebauer and colleagues (2013).

\begin{tabular}{llll}
\hline \multirow{2}{*}{ Model: Type of heterogeneity } & Fit Indices & & RMSEA \\
\cline { 2 - 3 } & Chi-square & CFI & .06 \\
\hline Model 1: & $\chi^{2}(265)=605.21$ & .88 & .05 \\
Social heterogeneity & $p<.001$ & .91 & .06 \\
Model 2: & $\chi^{2}(265)=497.55$ & .87 & .001 \\
Cultural heterogeneity & $p<.001$ & & \\
Model 3: & $\chi^{2}(265)=636.32$ & & \\
Performance-related heterogeneity & $p<.001$ & & \\
\hline
\end{tabular}

As already described above, the second research question (i.e., student teachers' attitudes towards heterogeneity and Big Five personality traits) was answered based on descriptive statistics for all subscales separately. In addition to those scores another parameter, namely the average scores over the three subscales of different forms of heterogeneity (i.e., the grand mean), was calculated for each subscale of type of attitude. This does not only give a suitable general statistical tendency across heterogeneity forms, but will also represent the statistical basis for further analyses in line with the third research question, in which the grand means are used as the variables of interest. Table 5 shows an overview of all statistical parameters.

Table 5. Student teachers' mean (M) and standard deviation (SD) for every subscale of the scale on attitudes towards heterogeneity and the Big 5

\begin{tabular}{lll}
\hline & $\mathrm{M}$ & $\mathrm{SD}$ \\
\hline Subscales for Attitudes & & \\
\hline Benefit (cognitive) & & \\
Social & 2.00 & 0.53 \\
Cultural & 2.24 & 0.45 \\
Performance-related & 1.93 & 0.60 \\
\hline
\end{tabular}




\begin{tabular}{lll}
\hline Grand mean & $\mathbf{2 . 0 6}$ & $\mathbf{0 . 4 1}$ \\
\hline Costs (cognitive) & 1.26 & 0.64 \\
Social & 1.29 & 0.58 \\
Cultural & 1.62 & 0.57 \\
Performance-related & $\mathbf{1 . 4 3}$ & $\mathbf{0 . 4 4}$ \\
Grand mean & & \\
\hline Negative emotions (motivational-affective) & 0.86 & 0.59 \\
Social & 0.95 & 0.57 \\
Cultural & 1.20 & 0.63 \\
Performance-related & $\mathbf{1 . 0 1}$ & $\mathbf{0 . 4 7}$ \\
Grand mean & & \\
\hline Intrinsic motivation (motivational-affective) & 1.84 & 0.59 \\
Social & 2.18 & 0.61 \\
Cultural & 1.91 & 0.58 \\
Performance-related & $\mathbf{1 . 9 9}$ & $\mathbf{0 . 4 7}$ \\
Grand mean & & \\
\hline Competence (behavioural) & 2.06 & 0.47 \\
Social & 2.03 & 0.43 \\
Cultural & 2.09 & 0.46 \\
Performance-related & $\mathbf{2 . 0 6}$ & $\mathbf{0 . 3 8}$ \\
\hline Grand mean & & 0.87 \\
\hline Subscales for Big 5 & 2.73 & 0.82 \\
Neuroticism & 1.72 & 0.96 \\
Openness to Experiences & 2.73 & 0.76 \\
Agreeableness & 2.42 & 0.90 \\
\hline Conscientiousness & 2.54 & \\
\hline
\end{tabular}

Analysing the descriptive statistics of all subscales (see Table 5), it can be seen that particularly on the cognitive scale benefit students scored relatively high compared to the other scales. With mean values between 1.93 and 2.00 on the three subscales including the various forms of heterogeneity and a grand mean of 2.06, scores lie significantly above the theoretical mean of 1.50 . This is also true for the descriptive data of the behavioural dimension of attitudes, which includes perceived competence of student teachers with regard to the three types of heterogeneity. Means reached values between 2.03 and 2.09 as well as a grand mean of 2.06, which also is higher than the aforementioned theoretical mean. However, compared to the mean scores on the scale benefit, scores on this subscale are closer to each other, which can be seen on the smaller standard deviations.

Comparing mean scores across the five personality traits (see Table 5) the opposite tendency of the pattern found in results for research question $2 \mathrm{a}$ can be observed. Specifically, results revealed scores of 2.73 on the scales extraversion and openness to experiences, while those found in the scales agreeableness and conscientiousness lie relatively close to each other with means of 2.42 and 2.54 respectively. Only with regard to the scale neuroticism findings show a significantly smaller score $(M=1.72)$, which represents a significant difference of roughly 1.00 compared to the two highest values.

The third research question (i.e., the effects of the Big Five personality traits on attitudes) was answered in two ways: On the one hand, the effects of all five personality traits (taken into account simultaneously) on each of the five measurements of attitudes towards heterogeneity were analysed applying multiple regression analyses (research question 3a). On the other hand, the effects of each of the Big Five personality traits on all five types of 
attitudes towards heterogeneity simultaneously were investigated using structural equation modelling (SEM; research question $3 b$ ).

For the question 3a, Table 6 summarizes the results of the conducted multiple regression analyses. A total of five models were analysed (represented by the columns in Table 6), one for each facet of attitudes towards heterogeneity (i.e., the subscales benefit, costs, negative emotions, intrinsic motivation, and perceived competence).

Table 6. Standardized regression coefficients beta for each of the Big Five personality traits on all five factors of attitudes towards heterogeneity separately (each factor of attitudes towards heterogeneity represents one separate statistical model) as well as standardized coefficients of explained variance for each of the models

\begin{tabular}{llllll}
\hline Subscale & $\begin{array}{l}\text { Benefit } \\
(\text { Model 1) }\end{array}$ & $\begin{array}{l}\text { Costs } \\
(\text { Model 2) }\end{array}$ & $\begin{array}{l}\text { Negative emotions } \\
(\text { Model 3) }\end{array}$ & $\begin{array}{l}\text { Intrinsic motivation } \\
\text { (Model 4) }\end{array}$ & $\begin{array}{l}\text { Compe-tence } \\
\text { (Model 5) }\end{array}$ \\
\hline F-statistic [F(5, 288)] & 1.31 & 1.60 & $9.63^{* * *}$ & $5.27^{* * *}$ & $7.98^{* * *}$ \\
Effect size $\left(\right.$ Cohen's $\left.f^{2}\right)$ & 0.01 & 0.01 & 0.15 & 0.07 & 0.12 \\
Extraversion & .08 & .04 & -.01 & .05 & $.18^{* *}$ \\
Neuroticism & .04 & $.16,{ }^{* *}$ & $.36^{* * *}$ & $-.13^{*}$ & $-.12^{*}$ \\
Openness to Experiences & .11 & -.04 & -.08 & .09 & .11 \\
Agreeableness & .01 & .01 & .05 & .09 & .03 \\
Conscientious-ness & .00 & -.03 & -.08 & $.19^{* *}$ & $.19^{* *}$ \\
Corrected $R^{2}$ & $R^{2}=.01$ & $R^{2}=.01$ & $R^{2}=.13$ & $R^{2}=.07$ & $R^{2}=.11$ \\
\hline Note. $*: \mathrm{p}<.05, * * \mathrm{p}<.01 ; * * *: \mathrm{p}<.001$. & & & &
\end{tabular}

Looking through the results depicted in Table 6, one can see that models 1 and 2 did not reveal significant F-values and are not statistically significant explained by any of the Big Five personality traits. With regard to the remaining three significant models the following results were found: For model 3, only neuroticism revealed a significant value in the model, which in total was able to explain roughly $13 \%$ of the variance within the scale measuring negative emotions towards heterogeneity. In particular, it can be said that if the score on the scale negative emotions increase by one standard deviation, neuroticism also goes up 0.36 standard deviations and vice versa. Similarly, neuroticism was also able to explain one part of the total of $6.80 \%$ variance explained in the fourth model, investigating student teachers' intrinsic motivation with regard to aspects related to heterogeneity as the dependent variable. However, in this case the coefficient revealed a negative value, leading to a decrease of resulting scores on the scale neuroticism in case of an increase of scores on the scale intrinsic motivation and vice versa. In addition to these two predictors, conscientiousness also was significant as a second positive predictor in this model. With a standardized beta score of .19 it revealed a higher coefficient than neuroticism with -.13. In Model 5, three predictors are significant and the model was able to explain $10.60 \%$ of the total variance in this variable. In particular, these variables are extraversion, neuroticism and conscientiousness, while neuroticism was the only score revealing a negative coefficient.

In the following paragraph, the results revealed on the basis of the five structural equation models conducted are introduced (question $3 \mathrm{~b}$ ). In particular, in each model the standardized effects of each of the Big Five personality traits on all five attitudes towards heterogeneity simultaneously were analysed. One example (with extraversion as the independent variable of interest) of the five resulting models is depicted below (Figure 1). 


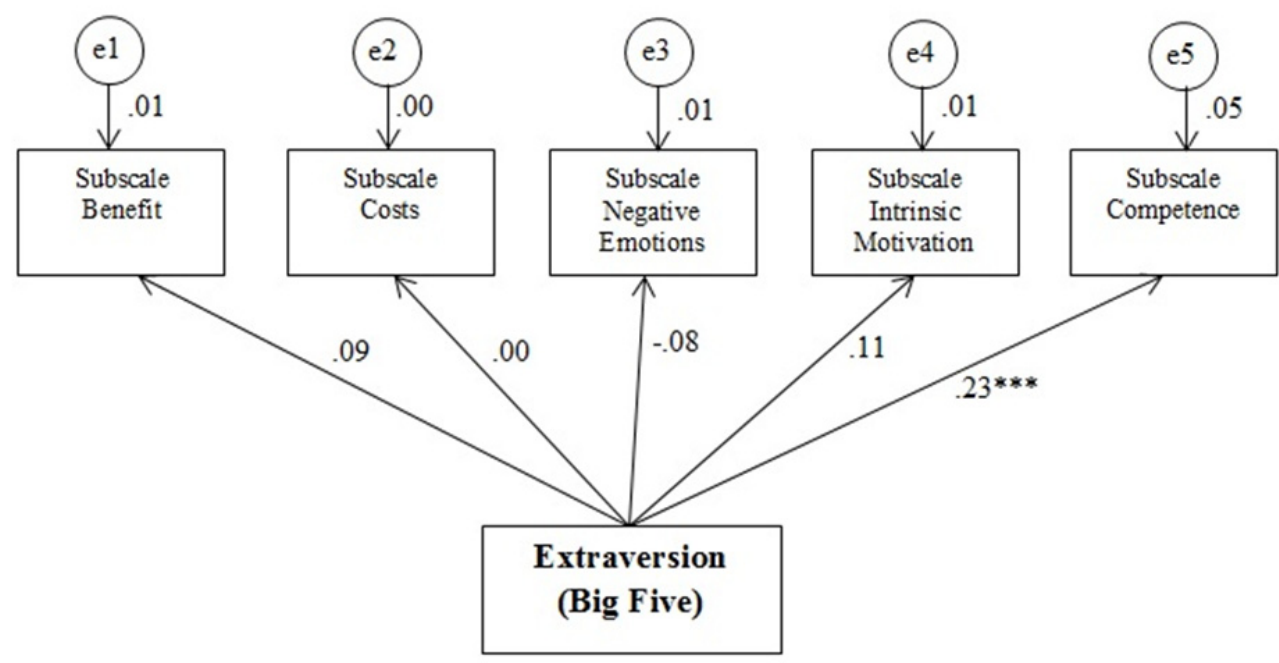

Figure 1. Example of a structural equation model with error terms (e1-e5) and standardized regression weights effects for the investigation of effects of extraversion (a Big Five personality trait) on the five subscale of attitudes towards heterogeneity (i.e., benefit, costs, negative emotions, intrinsic motivation, and competence)

Table 7 summarizes all results related to the five aforementioned conducted models. Although this table contains statistical coefficients similar to Table 6, the five different models important for this particular research questions are included within the lines, not the columns as was the case in Table 6.

Table 7. Standardized regression weights for effects of the Big Five personality traits on all five factors of attitudes towards heterogeneity (each Big Five personality trait represents one single statistical model)

\begin{tabular}{|c|c|c|c|c|c|c|}
\hline Subscale & $\begin{array}{c}\text { Chi-Square } \\
\text { statistic }\left[\chi^{2}(10)\right]\end{array}$ & Benefit & Costs & $\begin{array}{l}\text { Negative } \\
\text { emotions }\end{array}$ & $\begin{array}{l}\text { Intrinsic } \\
\text { motivation }\end{array}$ & Compe-tence \\
\hline $\begin{array}{l}\text { Extraversion } \\
\text { (Model 1) }\end{array}$ & $430.37 * * *$ & .09 & .00 & -.08 & .11 & $.23 * * *$ \\
\hline $\begin{array}{l}\text { Neuroticism } \\
\text { (Model 2) }\end{array}$ & $427.18^{* * *}$ & .03 & $.15^{* *}$ & $.36^{* * *}$ & $-.12 *$ & $-.14 *$ \\
\hline $\begin{array}{l}\text { Openness to Experiences } \\
\text { (Model 3) }\end{array}$ & $423.67 * * *$ & $.12 *$ & -.04 & -.10 & $.14 *$ & $.17 * *$ \\
\hline $\begin{array}{l}\text { Agreeableness } \\
\text { (Model 4) }\end{array}$ & $438.16^{* * *}$ & .03 & .01 & .04 & $.12 *$ & .07 \\
\hline $\begin{array}{l}\text { Conscientious-ness } \\
\text { (Model 5) }\end{array}$ & $431.15^{* * *}$ & .04 & -.02 & -.06 & $.21 * * *$ & $.23 * * *$ \\
\hline
\end{tabular}

As can be seen in Table 7, all models reveal significant chi square values, meaning that the data of the present study fit the suggested model represented by the five models. However, the significance of standardized regression weights differed significantly between these five models. In summary, the results show the following:

In model 1 only extraversion has a significant influence on students' competence-related attitudes towards heterogeneity. In comparison, neuroticism was a significant predictor for all but the dimension of perceived benefit through heterogeneity within the classroom. With regard to the negatively worded scales (i.e., costs, negative emotions), coefficients reveal positive scores, while with regard to intrinsic motivation and the perceived competence scale, scores are negative.

Furthermore, openness to experience (Model 3) is a significant positive predictor for the scales benefit, intrinsic motivation and competence with all coefficients being positive. With regard to the fourth model, agreeableness was only able to significantly predict the scale of intrinsic motivation. Finally, conscientiousness, analysed with 
Model 5, had significant positive effects on the attitude types intrinsic motivation and competence.

\section{Discussion}

\subsection{Discussion of Key Results and Implications for Teacher Education}

The first research question asked for the validity of the instrument by Gebauer and colleagues (2013), which could be supported with the present data set. It was shown that attitudes can be represented by five factors: Benefit, costs, intrinsic motivation, negative emotions and competence. Furthermore, different forms of heterogeneity could be separated. So, there is a questionnaire which is based on theoretical work and reflections on attitudes such as those conducted previously. The instrument allows measurements that provide a differentiated view of attitudes and does not over-emphasize the cognitive aspect of them, as it has been the case in many other instruments. Subscales, such as the one measuring perceived competence or intrinsic motivation with regard to dealing with heterogeneity, representing the behavioural and motivational-affective factor of attitudes respectively, differentiate the aforementioned more general overall picture of attitudes.

The second research question aimed at exploring student teachers' attitudes towards heterogeneity. Results revealed evidence for differences between the three forms of heterogeneity in the present sample. In particular, higher scores are found on the subscales measuring cultural and social heterogeneity (i.e., benefit, motivation and perceived competence) in contrast to the performance-related heterogeneity facet. The fact that differences between different forms and types of students' attitudes can be found in the present data set supports the benefit of this applied instrument, which enables a detailed differentiation and consequently leads to more detailed insights (see research question 1). This is in line with the aforementioned statement, revealing that one cannot talk about one general attitude towards heterogeneity. By calculating a general mean value, for statistical reasons, a more general description of students' attitudes towards heterogeneity within the classroom was possible. Specifically, those attitudes can be described as revealing high values in perceived benefit, medium costs, low negative emotions and a positive intrinsic motivation as well as a positive perception of one's own competence to effectively handle this challenge in the classroom. With those findings, the study supports other results, which found positive attitudes towards heterogeneity in teachers and to some extent in students as well (e.g., Avramidis \& Norwich, 2002).

The main goal of the third research question was to investigate the effects of the Big Five personality traits on the particular factors of attitudes towards heterogeneity. Analysing the variance explained by all three models in a first step, it can be seen that personal characteristics only have a small effect on the particular attitude dimensions. Investigating these findings in more detail, results reveal neuroticism to be related to negative emotions, and lower values on neuroticism as well as higher ones on the scale measuring conscientiousness to have an effect on intrinsic motivation. Similarly, higher scores on the extraversion and conscientiousness scales as well as lower values on neuroticism were found to have a positive influence on perceived competence. At the same time, it is counterintuitive that extraversion, openness to experience and agreeableness do not have significant influences in all models. Finally it can be assumed that people, who are open, have more positive attitudes.

In line with the second part of the research question we investigated the influence of all Big Five personality traits on the five dimensions of attitudes towards heterogeneity. Through these analyses, certain relationships became clearer. In particular, they revealed the following results:

- Extraversion has a positive effect on perceived competence with regard to dealing with heterogeneity.

- Neuroticism leads to higher perceived costs, more negative emotions, and lower values in intrinsic motivation as well as in perceived competence.

- Openness to experiences effects perceived benefit, intrinsic motivation and perceived competence positively.

- Agreeableness only has a statistically significant influence on intrinsic motivation.

- Higher levels on the conscientiousness scale lead to more intrinsic motivation and perceived competence.

Merging both research questions, one can say that the Big Five personality traits generally do not contribute significantly to the variance explained in the different dimensions of attitudes towards heterogeneity. The three traits with the most informative values, however, are neuroticism, conscientiousness, and openness to experience. Furthermore, it is evident that those personality-related characteristics have a particular effect on intrinsic motivation and perceived competence.

What implications can be derived from these results? On the one hand, it can be said that the instrument applied in the present study is suitable for the identification of various attitudes. Similarly, it was found that distinguishing between different forms of heterogeneity, which can be realised using the applied instrument as it measures all five 
attitude dimensions separately, is beneficial. This way, factors of future teacher training that has to be worked on can be identified. For example, in the case of positive motivation and emotions, teacher training can be used to deal with possible inadequate competences via critical incident analyses focusing on challenging situations referring to a context of heterogeneity. Moreover, efforts can be made in reducing the cost of certain forms of heterogeneity, for example through sufficient resources. The separation on the basis of different dimensions of heterogeneity should also be considered in teacher trainings: Considering a mixture of dimensions in seminars, lectures, etc., leads to heterogeneity being generally perceived as negative, whereas ethno-cultural diversity, for example, is perceived as very enriching. In order to keep a positive attitude it is therefore necessary to provide support for student teachers to critically reflect on their attitudes.

With regard to the Big Five personality traits, on the other hand, the revealed small influence on attitudes towards heterogeneity can be interpreted as 'settling' due to the fact that they are human characteristics that are difficult to change in general. However, neuroticism and conscientiousness were found to be the two characteristics with the most significant influence. Based on findings suggesting that conscientiousness and neuroticism increase with age (e.g., Roberts, Walton, \& Viechtbauer, 2006), these characteristics might be important to attend to in different phases of teacher trainings. Findings suggesting a relationship between neuroticism and life course functioning further support the important role of neuroticism in general, and also in the teaching profession (e.g., Soldz \& Vaillant, 1999).

Additionally, both aforementioned variables, attitudes towards heterogeneity and the Big Five personality traits, can be applied as support for selection processes and during career counselling sessions for future student teachers. Not to 'sort out' those that would not seem to be eligible, but rather as an opportunity for future teachers to recognize, reflect and work on their own attitudes before and at the beginning of their studies (for example, in the context of case studies, accompanied internships, etc.; see also Mayr, 2001).

\subsection{Limitations and Further Research}

The sample of the present research study includes students at the beginning of their teaching studies without much practical experience. Due to these circumstances, they can be seen as novice teachers. However, this also implies that no conclusions about later points in time during their professional career or the perceptions of experienced teachers can be drawn. Changes through further training and practical experiences are possible, which has already been shown with regard to inclusion. Furthermore, it is important to keep in mind that the data collection process was only realized in one single university. It is therefore important to validate this instrument in other university contexts and additional samples in further investigations. Similarly, this instrument has only been applied with student teachers, a validation and verification based on a sample of teachers, who have experiences with a variety of students and also possibly with regard to inclusion and other aspects of the teaching profession, would be essential and desirable. Furthermore, an analysis using a longer version of an instrument measuring the Big Five personality traits, such as the NEO PI-R by Costa and McCrae (1992), would be of interest in order to reveal more detailed insight.

Finally, the present study was realized using a sample of a university in Germany. However, as already described above, the increase of heterogeneity in the classrooms is a European, and even global phenomenon. Therefore, it would be desirable to also replicate the study in other countries. This could give insight into the question whether the revealed results are transferable and what exact conclusions can be drawn based on those findings.

\section{References}

Agyemang, F. G., Dzandu, M. D., \& Boateng, H. (2016). Knowledge sharing among teachers: The role of the Big Five personality traits. VINE Journal of Information and Knowledge Management Systems, 46(1), 64-84. https://doi.org/10.1108/VJIKMS-12-2014-0066

Ajzen, I. (2001). Nature and operation of attitudes, Annual Review of Psychology, 52, 27-58. https://doi.org/10.1146/annurev.psych.52.1.27

Ajzen, I., \& Fishbein, M. (2000). Attitudes and the attitude-behaviour relation: Reasoned and automatic processes, European Review of Social Psychology, 11(1), 1-33. https://doi.org/10.1080/14792779943000116

Asendorpf, J. B. (2007). Psychologie der Persönlichkeit [Psychology of personality] (4th ed.). Heidelberg: Springer. https://doi.org/10.1007/978-3-540-71685-3

Ashton, M. C. (2013). Individual differences and personality (2nd ed.). Waltham: Elsevier Inc.

Avramidis, E., \& Norwich, B. (2002). Teacher's attitudes towards integration/inclusion: A review of the literature. European Journal of Special Needs Education, 17, 129-147. https://doi.org/10.1080/08856250210129056 
Blossfeld, H.-P., Bos, W., Lenzen, D., Müller-Böling, D., Oelkers, J., Prenzel, M., \& Wößmann, L. (Eds.) (2007). Bildungsgerechtigkeit. Jahresgutachten 2007 [Educational justice. Annual report 2007]. Wiesbaden: VS Verlag.

Bourdieu, P. (1979). Distinction: A social critique of the judgement of taste. Boston: Harvard University Press.

Bryer, F., Grimbeek, P., Beamish, W., \& Stanley, A. (2004). How to use the Parental Attitudes to Inclusion scale as a teacher tool to improve parent-teacher communication. Issues In Educational Research, 14, 105-120.

Byrne, B. M. (2009). Structural equation modeling with AMOS: Basic concepts, applications, and programming (2nd ed.). New York: Routledge.

Carter, P. L., \& Darling-Hammond, L. (2016). Teaching diverse learners. In D. H. Gitomer \& C.A. Bell (Eds.), Handbook of research on teaching (pp. 593-638). Washington: American Educational Research Association. https://doi.org/10.3102/978-0-935302-48-6_9

Cattell, R. B. (1947). Confirmation and clarification of primary personality factors. Psychometrika, 12(3), 197-220. https://doi.org/10.1007/BF02289253

Cho, N., Li, G.Z. and Su, C.J. (2007). Empirical study on the effect of individual factors in knowledge sharing by knowledge type. Journal of Global Business and Technology, 3(2), 1-16.

Costa, P. T., \& McCrae, R. (1992) Revised NEO Personality Inventory (NEO-PI-R) and NEO Five-Factor Model (NEO-FFI) Professional manual. Odesa, FL: Psychological Assessment Centre.

De Boer, A., Pijl, S., \& Minnaert, A. (2011). Regular primary schoolteachers' attitudes towards inclusive education: A review of the literature. International Journal of Inclusive Education, 15(3), 331-353. https://doi.org/10.1080/13603110903030089

Dignath, C. (2017, August/September). Teachers' beliefs regarding heterogeneous classrooms - a systematic literature review. Paper presented at the 17th Biennial EARLI Conference for Research on Learning and Instruction, Tampere, Finland.

Dong, Y., \& Peng, C.-Y. J. (2013). Principled missing data methods for researchers [Adobe DX reader version]. https://doi.org/10.1186/2193-1801-2-222

Eagly, A. H., \& Chaiken, S. (1993). The psychology of attitudes. Fort Worth, TX: Harcourt Brace Jovanovich College Publishers.

Eagly, A. H., \& Chaiken, S. (1998). Attitude, structure and function. In D. T. Gilbert, Susan T. Fisk, \& G. Lindsey (Eds.), Handbook of social psychology (pp. 269-322). New York: McGowan-Hill.

Funder, D. C. (2001). Personality. Annual Review of Psychology, 52, 197-221. https://doi.org/10.1146/annurev.psych.52.1.197

Gao, M., \& Liu, Q. (2013). Personality traits of effective teachers represented in the narratives of American and Chinese preservice teachers: A cross-cultural comparison. International Journal of Humanities and Social Science, 3(2), 84-95.

Gebauer, M. M., McElvany, N., \& Klukas, S. (2013). Einstellungen von Lehramtsanwärterinnen und Lehramtsanwärtern zum Umgang mit heterogenen Schülergruppen in Schule und Unterricht [Attitudes of future teachers regarding dealing with heterogeneous groups of students in schools]. In N. McElvany, M. M. Gebauer, W. Bos, \& H. G. Holtappels (Eds.), Jahrbuch der Schulentwicklung (pp. 191-216). Weinheim: Juventa.

Gerber, A. S., Huber, G. A., Doherty, D., \& Dowling, C. M. (2011). The Big Five personality traits in the political $\begin{array}{lllll}\text { arena. Annual Review of Political } & \text { Science, } & \text { 14, 287. }\end{array}$ https://doi.org/10.1146/annurev-polisci-051010-111659

Goldberg, L. R. (1981) Language and individual differences: The search for universals in personality lexicons. In L. Wheeler (Ed.), Review of personality and social Psychology (pp. 141-165). Beverly Hills, CA: Sage.

Goldberg, L. R. (1992). The development of markers for the Big-Five factor structure. Psychological Assessment, 4, 26-42. https://doi.org/10.1037/1040-3590.4.1.26

Goodman, G., Arbona, C., \& Dominguez de Rameriz, R. (2008). High-stakes, minimum-competency exams: How competent are they for evaluating teacher competence?. Journal of Teacher Education, 59, 24-39. https://doi.org/10.1177/0022487107309972 
Gurven, M., Rueden, C. V., Massenkoff, M., Kaplan, H., \& Vie, M. L. (2013). How universal is the Big Five? Testing the Five Factor Model of personality variation among forager-farmers in the Bolivian Amazon. Journal of Personality and Social Psychology, 104(2), 354-370. https://doi.org/10.1037/a0030841

Hachfeld, A., Schroeder, S., Anders, Y., Hahn, A., \& Kunter, M. (2012). Multikulturelle Überzeugungen. Herkunft oder Überzeugung? Welche Rolle spielen der Migrationshintergrund und multikulturelle Überzeugungen für das Unterrichten von Kindern mit Migrationshintergrund? [Multicultural attitudes. Ancestry or belief? What role do the migration background and multicultural believes play with regard to teaching students with migration backgrounds?] Zeitschrift für pädagogische Psychologie, 26, 101-120. https://doi.org/10.1024/1010-0652/a000064

Hu, L - T., \& Bentler, P. (1999). Cutoff criteria for fit indexes in covariance structure analysis: Conventional criteria versus new alternatives. Structural Equation Modeling: A Multidisciplinary Journal, 6, 1-55. https://doi.org/10.1080/10705519909540118

John, O. P., Donahue, E. M., \& Kentle, R. L. (1991). The Big Five Inventory - Version 4a and 54. Berkeley, CA: University of California.

John, O. P., Naumann, L. P., \& Soto, C. J. (2008). Paradigm shift to the integrative Big Five trait taxonomy: History, measurement, and conceptual issues. In O. P. John, R. W. Robins, \& L. A. Pervin (Eds.), Handbook of personality: Theory and research (pp. 114-158). New York: Guilford Press.

Judge, T. A., Heller, D., \& Mount, M. K. (2002). Five-factor model of personality and job satisfaction: A meta-analysis. Journal of Applied Psychology, 87(3), 530-541. https://doi.org/10.1037/0021-9010.87.3.530

Kiel, E., Syring, M. \& Weiß, S. (2017). How can Intercultural School Development succeed? The Perspective of Teachers and Teacher Educators. Pedagogy, Culture and Society, 25(2), 243-261. https://doi.org/10.1080/14681366.2016.1252421

Kunter, M., Klusmann, U., Baumert, J., Richter, D., Voss, T., \& Hachfeld, A. (2013). Professional competence of teachers: Effects on instructional quality and student development. Journal of Educational Psychology, 105, 805-820. https://doi.org/10.1037/a0032583

Lei, P.-W., \& Wu, Q. (2007). Introduction to Structural Equation Modeling: Issues and practical considerations. $\begin{array}{lllll}\text { Educational Measurement Issues and } & \text { 33-43. }\end{array}$ https://doi.org/10.1111/j.1745-3992.2007.00099.x

Little, R. J. A. (1988). A test of missing completely at random for multivariate data with missing values. Journal of the American Statistical Association, 83, 1198-1202. https://doi.org/10.1080/01621459.1988.10478722

Loreman, T., Earle, C., Sharma, U., \& Forlin, C. (2007). The development of an instrument for measuring pre service teachers' sentiments, attitudes, and concerns about inclusive education. International Journal of Special Education, 22(2), 150-159.

Maio, G., \& Haddock, G. (2010). The psychology of attitudes and attitude change. London: Sage.

Matzler, K., Renzl, B., Mueller, J., Herting, S., \& Mooradian, T. A. (2008). Personality traits and knowledge sharing. Journal of Economic Psychology, 29, 301-313. https://doi.org/10.1016/j.joep.2007.06.004

Mayr, J. (2001). Career counselling for teachers. Context - European Education Magazine, 25, 11.

McCrae, R. R., \& Costa, P. T. (1990). Personality in adulthood. New York: Guilford Press.

Mercado, C. I. (2001). The learner: "Race", "ethnicity", and linguistic difference. In V. Richardson (Ed.), Handbook of research on teaching (pp. 668-694). Washington: American Educational Research Association.

Merk, S., Bohl, T., Cramer, C., Dai, N. \& Syring, M. (in press). The construct validity of student teachers attitudes regarding the heterogeneity of pupils. Journal of Educational Research Online.

Ostendorf, F., \& Angleitner, A. (1994). The five-factor taxonomy: Robust dimensions of personality description. Psychologica Belgica, 34(4), 175-194.

Paine, L., Bloemeke, S., \& Aydarova, O. (2016). Teachers and teaching in the context of globalization. In D. H. Gitomer \& C. A. Bell (Eds.), Handbook of research on teaching (pp. 717-786). Washington: American Educational Research Association. https://doi.org/10.3102/978-0-935302-48-6_11

Rammstedt, B., \& John, O. P. (2007). Measuring personality in one minute or less: A 10-item short version of the Big Five Inventory in English and German. Journal of Research in Personality, 41, 203-212. https://doi.org/10.1016/j.jrp.2006.02.001 
Rammstedt, B., Kemper, C. J., Klein, M. C., Beierlein, C., \& Kovaleva, A. (2014). Big Five Inventory (BFI-10). Zusammenstellung sozialwissenschaftlicher Items und Skalen. https://doi.org/10.6102/zis76

Richardson, V. (1996). The role of attitudes and beliefs in learning to teach. In J. Sikula, T. Buttery, \& E. Guyton (Eds.), Handbook of research on teacher education (pp. 102-106). New York: Macmillan.

Ring, E. (2005). Barriers to inclusion: A case study of a pupil with severe learning difficulties in Ireland. European Journal of Special Needs Education, 20, 41-56. https://doi.org/10.1080/0885625042000319070

Roberts, B. W., Walton, K. E., \& Viechtbauer, W. (2006). Patterns of mean-level change in personality traits across the life course: A meta-analysis of longitudinal studies. Psychological Bulletin, 132(1), 1-25. https://doi.org/10.1037/0033-2909.132.1.1

Rosenberg, M. J., \& Hovland, C. I. (1960). Cognitive, affective and behaviour al components of attitudes. In C. I. Hovland \& M. J. Rosenberg (Eds.), Attitude organization and change: An analysis of consistency among attitude components (pp. 1-14). New Haven: Yale University Press.

Ryser, V. - A. (2015). Psychometric properties of extra-short Big Five personality measures in multi-topic surveys: Documenting personality traits in the SHP and MOSAiCH. FORS Working Paper Series, paper 2015-5. Lausanne: FORS.

Sharma, U., Loreman, T., \& Forlin, C. (2012). Measuring teacher efficacy to implement inclusive practices: An international validation. Journal of Research in Special Educational Needs, 12(1), 12-21. https://doi.org/10.1111/j.1471-3802.2011.01200.x

Smith, E. R., \& Mackie, D. M. (2010). Affective processes. In R. F. Baumeister \& E. J. Finkel (Eds.), Advanced social psychology (pp. 131-145). London: Sage. https://doi.org/10.4135/9781446200919.n8

Soldz, S., \& Vaillant, G. E. (1999). The Big Five personality traits and the life course: A 45-year longitudinal study. Journal of Research in Personality, 33(2), 208-232. https://doi.org/10.1006/jrpe.1999.2243

Stoiber, K. C., Gettinger, M., \& Goetz, D. (1998). Exploring factors influencing parents` and early childhood practitioners' beliefs about inclusion. Early Childhood Research Quarterly, 13(1), 107-124. https://doi.org/10.1016/S0885-2006(99)80028-3

Teven, J. (2007). Teacher caring and classroom behaviour: Relationships with student affect and perceptions of teacher competence and trustworthiness. Communication Quarterly, 55(4), 433-450. https://doi.org/10.1080/01463370701658077

Tupes, E. C., \& Christal, R. C. (1992). Recurrent personality factors based on trait ratings. Journal of Personality, 60, 225-251. https://doi.org/10.1111/j.1467-6494.1992.tb00973.x

United Nations (2006). Convention on the rights of persons with disabilities. New York: United Nations.

Voss, T., Kleickmann, T., Kunter, M., \& Hachfeld, A. (2013). Mathematics teachers' beliefs. In M. Kunter, J. Baumert, W. Blum, U. Klusmann, S. Krauss, \&d M. Neubrand (Eds.), Cognitive activation in the mathematics classroom and professional competence of teachers: Results from the COACTIV project (pp. 249-272). New York: Springer.

Wood, W. (2000). Attitude change: Persuasion and social influence. Annual Review of Psychology, 51, 539-570. https://doi.org/10.1146/annurev.psych.51.1.539

Yildrim, E. (2012). The investigation of the teacher candidates' attitudes towards teaching profession according to their demographic variables. Procedia - Social and Behavioural Sciences, 46, 2352-2355. https://doi.org/10.1016/j.sbspro.2012.05.483

Zanna, M., \& Rempel, J. K (1988). Attitudes: A new look at an old concept. In D. Bar-Tal \& A. W. Kruglanski (Eds.), The social psychology of knowledge (pp. 315-334). Cambridge: Cambridge University Press.

\section{Copyrights}

Copyright for this article is retained by the author(s), with first publication rights granted to the journal.

This is an open-access article distributed under the terms and conditions of the Creative Commons Attribution license (http://creativecommons.org/licenses/by/4.0/). 